\title{
DROSERA ERICGREENII - ERIC GREEN'S SUNDEW
}

ANDREAS FLEISCHMANN • Landsberg•Germany• fleischmann@lrz.uni-muenchen.de

Keywords: ecology, cultivation, Drosera ericgreenii

Drosera ericgreenii is a perennial sundew species from the Western Cape of South Africa, which was first discovered by Eric Green near the town of Franschhoek in Stellenbosch municipality, and which was formally described in 2008 (Fleischmann et al. 2008). The plant forms short stems with age, usually not exceeding $10 \mathrm{~cm}$ in height, which bear obovate to narrowly oblong leaves on short internodes. The leaves range in color from dull green to yellowish green (in plants growing in full sun); the entire petiole and lower surface of the lamina is covered with patent, long white hairs, which gives the entire plant a hirsute appearance (Fig. 1a, b). The triangular papery stipules are white or reddish as long as the leaves are active and green, and dry brownish as the leaves desiccate. The flower scapes are arcuate from the base, covered with long white, patent hairs in the lower part, and deep red in color (hence contrasting well with the green leaves; Fig. 1a, b). The upper part of the scape, the pedicels and the calyx are covered with small, red glandular hairs. The pink flowers are approximately $2 \mathrm{~cm}$ in diameter and last for one day only; the petals are cuneate, the 3 styles are each divided to the base; the shape of the stigmatic tips (a useful diagnostic character in South African Drosera species) are lobed or divided (Fig. 1c). The seed is narrowly fusiform in shape, and produced in large numbers.

Drosera ericgreenii is somewhat reminiscent of the related $D$. hilaris, from which it differs in having membranous stipules present at the base of its leaves (in D. hilaris, the stipules are reduced to small, inconspicuous setae, and thus are barely visible), by its much shorter stems, inflorescence scapes that are arcuately ascending at the base (the scapes are emerging straight upwards in $D$. hilaris), and by having long, non-mucilaginous unifacial glands ("snap tentacles") at the apical margin of the leaves (no such glands present on the lamina of mature leaves in D. hilaris). Moreover, the flower structure, namely the shape of the stigmatic tips of the styles, also differs from $D$. hilaris. The plant has previously been referred to by the informal names "Drosera sp. stemless hilaris" or “D. sp. Franschhoek" (Miyamoto 2002).

\section{Habitat}

Drosera ericgreenii occurs in a very restricted geographical range, confined to mountain slopes near the town of Franschhoek in Western Cape Province, South Africa. Here it grows on damp sandy acidic soils in xerophytic fynbos vegetation (a typical vegetation type of the Cape floral area, it is a drought and fire adapted ericoid scrubland; the name "fynbos" is derived from Afrikaans language and means "fine bush", referring to the usually small, needle-like leaves of many species growing there). Usually the plants grow solely or in small clusters in the partial shade of small rocks or beneath shrubs (Fig. 1a). There the perennial D. ericgreenii is often found close to the summer dormant $D$. cistiflora. While the latter always dies back above ground in summer, surviving the dry season by its long, fleshy roots, $D$. ericgreenii will simply slow its growth during the hottest months, producing smaller leaves after flowering, and may eventually even die back to a resting, apical bud (a strategy likewise observed in the stem-forming species, D. hilaris, D. ramentacea, and D. glabripes). 
Unfortunately, the beautiful $D$. ericgreenii is far from being an easy, weedy species in cultivation - certainly it is not a beginner's plant to grow. It is a South African montane species of damp sandy soils (but not a bog plant!), and therefore a bit more demanding in cultivation, especially in terms of temperature and watering. Like several other mountain sundews from the Cape (D. glabripes, D. hilaris, D. ramentacea, D. esterhuyseniae, D. cuneifolia) it prefers cool temperatures, especially of the soil. Moreover, it has an extensive root system consisting of long tap roots, which can reach up to at least $50 \mathrm{~cm}$ in length, and which are adapted to grow into deeper soil naturally, in order to reach moisture. If the roots are exposed to hot temperatures for too long, and especially if the plant is kept in soaking wet soil - both conditions that are likely to occur if the plants are kept in tray system permanently, and if planted in shallow pots - the root system is likely to be damaged and will rot easily. I grow D. ericgreenii and the other five above-mentioned South African Drosera species in very tall plastic pots of $c a .20 \mathrm{~cm}$ depth and $c a .15 \mathrm{~cm}$ diameter (2-3 liter containers). By using a very open soil mix consisting of peat, coarse-grained quartzitic sand, and perlite (in about equal parts), I try to provide enough aeration for the roots. I also maintain the soil mix only moist, not soaking wet. The deep pots also allow me to keep these plants in a tray system at the greenhouse, without being permanently wet like the bog species $D$. capensis or D. aliciae. I let the trays dry up completely before watering them again, especially during summer, when the plants slow their growth and reduce the size and number of leaves. Good shading and air movement both seem to be important, too, especially during the hot summer months. Providing good growing conditions, $D$. ericgreenii can be persistent and long-living in cultivation, flowering each year in early spring. The flowers need to be hand-pollinated in order to set seed. Although they can be selfed, fertile seed set is higher if two different individuals are cross-pollinated. Drosera ericgreenii can be propagated vegetatively by root cuttings, however it does not reproduce from leaf cuttings (likewise in the other five above-mentioned, dry-loving Drosera species, leaf cuttings do not work either). Hopefully this nice species will enter more Drosera collections worldwide soon!

\section{Etymology}

Drosera ericgreenii was named in honor of the South African carnivorous plant expert Eric Green, who discovered countless localities of carnivorous plants in the Cape area, and who originally discovered several new species of Drosera (including D. slackii, D. rubrifolia, D. coccipetala, D. cistiflora "Eitz", D. afra, and others). Eric also can be traced back as the original seed source of almost all South African Drosera which entered carnivorous plant collections worldwide in the past decades from the late 1970's on.

When Robert Gibson, Fernando Rivadavia, Stewart McPherson, Kirk "Füzzy" Hirsch, and I met Eric on our trip to Cape Town, we were all deeply impressed by his profound knowledge of South African plants, by his photographic memory of carnivorous plant locations, but especially will remember his hospitality and cordiality. Eric kindly and enthusiastically shared his location data with us, including how to find the "stemless D. hilaris" site, which we visited in 2006 to study the plant we only knew from photographs and herbarium specimens in its natural habitat, allowing the formal description to be made in 2008.

We did not have to think long when it came to finding an appropriate name for this new species - it was clear to all of us that finally a plant name should be dedicated to Eric Green.

However, we did not tell Eric about this plan, keeping it a secret while preparing the plant de- 

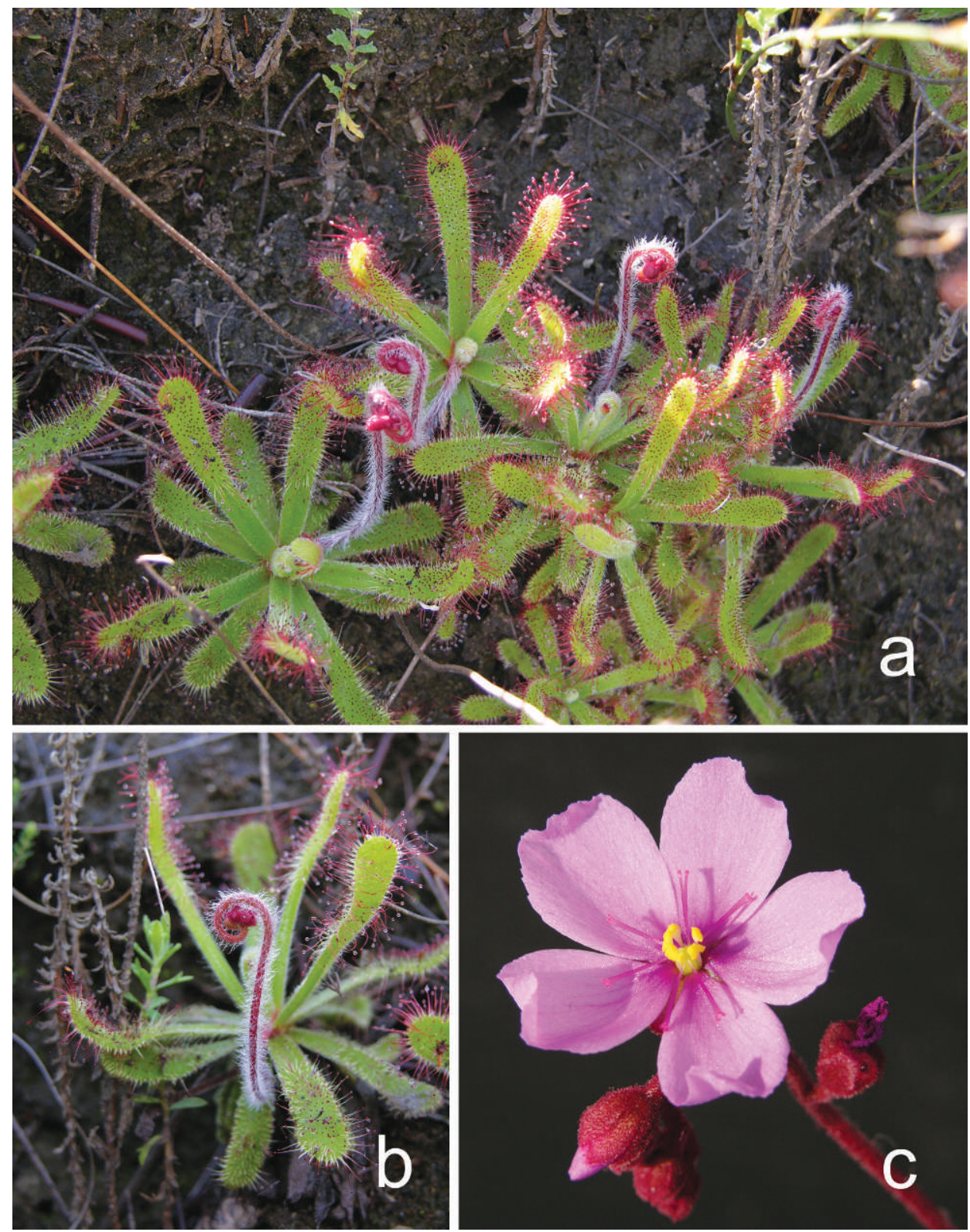

Figure 1: a) A group of Drosera ericgreenii in habitat near Franschhoek, South Africa. b) Drosera ericgreenii with emerging inflorescences, Franschhoek, South Africa. Note the very hairy scape, which is arcuate at the base. In the related $D$. hilaris, the scape is growing upright from the center of the plant. c) Flower of Drosera ericgreenii (cultivated specimen). All photos by A. Fleischmann.

scription. Thus Eric was very happily surprised when I sent him the printed botanical description right after it was published. He replied with a very touching letter: 
"I am Honoured, more than honoured, and absolutely amazed that being fascinated by the most beautiful plant species in the world for a 'few' years in ones lifetime could give one the satisfaction of achieving something that makes one feel so good.

I realise many names must of been bantered about, Why me????, when friends mentioned naming a plant in my honour in the past we would always laugh and say this or that beautiful reddish plant will one day be named greenii, not in my wildest dreams did I ever believe a plant would be burdened with my name, what an amazing honour.

Gentlemen Thank You."

Apparently he was deeply moved by this, because a few days later, he sent another short email to me:

"It is an amazing gift, thank You, I still, after 3 days find it difficult to believe what an honour I have received.

It will be great to see You in Cape Town once again in the near future.

\section{ALL THE BEST Eric".}

Unfortunately, I was not able to make it back to Cape Town in the past years to meet Eric again, but we kept some correspondence by mail. Eric later told me that he took a copy of the D. ericgreenii article everywhere with him in the car, and proudly showed it to friends and family.

Thank you Eric for your contributions to the knowledge and cultivation of South African carnivorous plants!

References:

Fleischmann, A., Gibson, R., and Rivadavia, F. 2008. Drosera ericgreenii (Droseraceae), a new species from the fynbos of South Africa. Bothalia 38: 141-144.

Miyamoto, M. 2002. Drosera of South Africa. The detail view of an undecided kind, and comparison of a definite kind [sic!]. Journal of the Japanese Carnivorous Plant Society 8: 15-18.

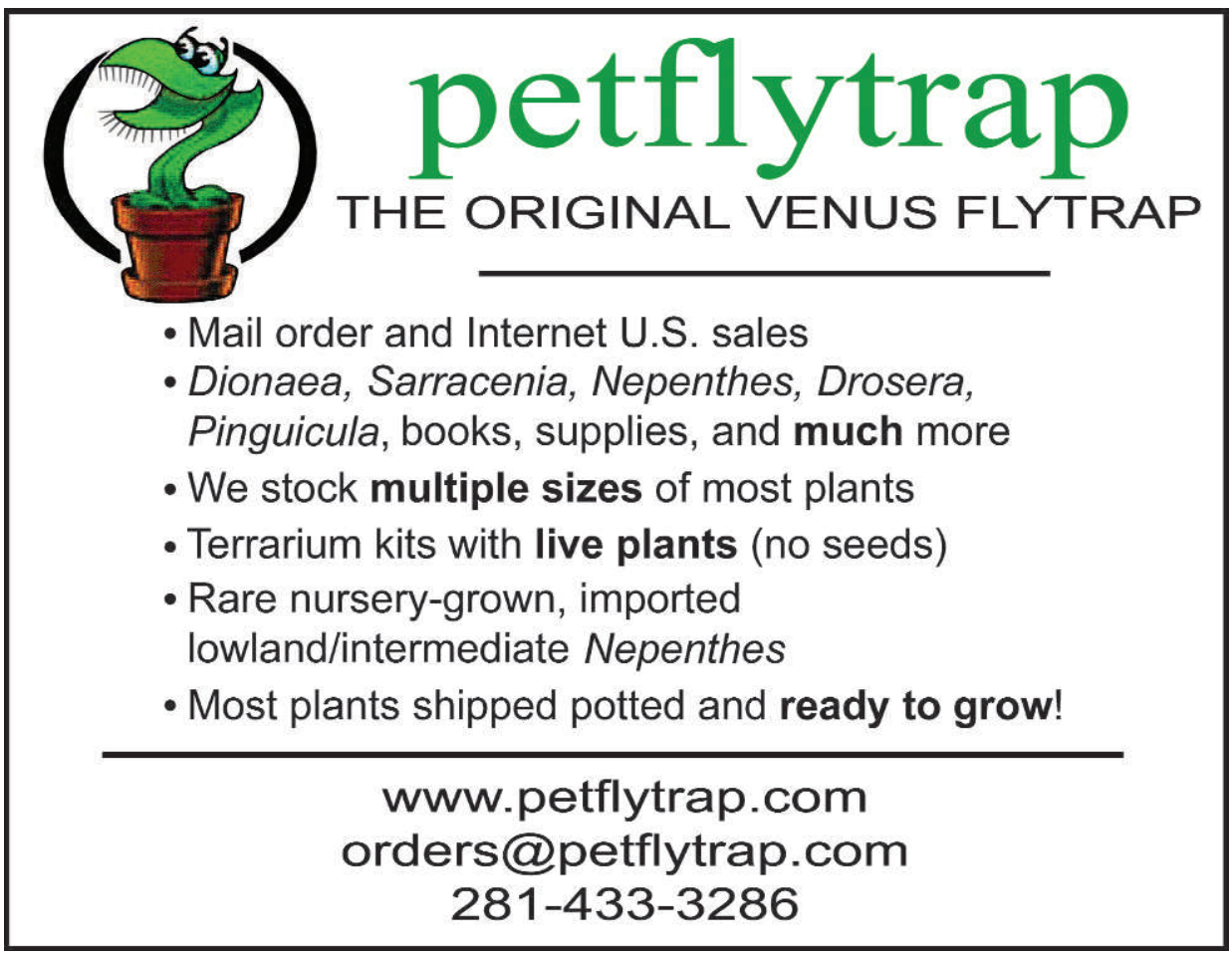

